\title{
1,1-Bis(3'-indolyl)-1-(p-bromophenyl)methane and related compounds repress survivin and decrease $\gamma$-radiation-induced survivin in colon and pancreatic cancer cells
}

\author{
SANDEEP SREEVALSAN $^{1}$, INDIRA JUTOORU ${ }^{1}$, GAYATHRI CHADALAPAKA $^{1}$, \\ MICHAEL WALKER $^{2}$ and STEPHEN SAFE ${ }^{1,3}$
}

\begin{abstract}
Departments of ${ }^{1}$ Veterinary Physiology and Pharmacology, ${ }^{2}$ Large Animal Medicine and Surgery,
Texas A\&M University, College Station, TX 77843; ${ }^{3}$ Institute of Biosciences and Technology,

Texas A\&M Health Science Center, Houston, TX 77030, USA
\end{abstract}

Received June 17, 2009; Accepted August 3, 2009

DOI: 10.3892/ijo_00000436

\begin{abstract}
Bis(3'-indolyl)-1-(p-bromophenyl)methane (DIM-C-pPhBr) and the 2,2'-dimethyl analog (2,2'-diMeDIM$\mathrm{C}-\mathrm{pPhBr}$ ) inhibit proliferation and induce apoptosis in SW480 colon and Panc28 pancreatic cancer cells. In this study, treatment with 10-20 $\mu \mathrm{M}$ concentrations of these compounds for $24 \mathrm{~h}$ induced cleaved PARP and decreased survivin protein and mRNA expression in both cell lines. However, results of time course studies show that DIM-C-pPhBr and 2,2'-diMeDIM-C-pPhBr decrease survivin protein within $2 \mathrm{~h}$ after treatment, whereas survivin mRNA levels were decreased only at later time-points indicating activation of transcriptionindependent and -dependent pathways for downregulation of survivin. In addition, we also observed that $\gamma$-radiation inhibited pancreatic and colon cancer cell growth and this was associated with enhanced expression of survivin after 24 (SW480) or 24 and $48 \mathrm{~h}$ (Panc28) and correlated with previous studies on the role of survivin in radiation-resistance. However, in cells co-treated with $\gamma$-radiation plus DIM-C-pPhBr or 2,2'-diMeDIM-C-pPhBr, induction of survivin by $\gamma$-radiation was inhibited after co-treatment with both compounds, suggesting applications for these drugs in combination cancer chemotherapy with $\gamma$-radiation.
\end{abstract}

\section{Introduction}

Survivin is a $16.5 \mathrm{kDa}$ protein and a member of the inhibitor of apoptosis (IAP) family of proteins that suppress caspase-3,

Correspondence to: Dr Stephen Safe, Department of Veterinary Physiology and Pharmacology, Texas A\&M University, College Station, TX 77843-4466, USA

E-mail: ssafe@cvm.tamu.edu

Key words: DIM analogs, survivin downregulation, $\gamma$-radiationinduced survivin
-7 and -9 and thereby inhibits both the extrinsic and intrinsic apoptotic pathways (1-3). In addition to the anti-apoptotic activity of survivin, this protein also acts as a subunit of the chromosomal passenger complex and plays a role in cell division and cell cycle control (4). Survivin expression in normal tissues is variable (5-9); however, several studies show that survivin is more highly expressed in precancerous and tumor tissue derived from most solid tumors and hematological malignancies $(3,5,10,11)$. Intuitively, overexpression of survivin and other IAPs is not unexpected since cancer cells and tumors typically exhibit deregulated proliferative and survival pathways. High levels of survivin expression in cancer cells are due, in part, to several factors which regulate survivin at the transcriptional and posttranscriptional level. For example, several cancer cell lines overexpress specificity protein (Sp) transcription factors $\mathrm{Sp} 1, \mathrm{Sp} 3$ and $\mathrm{Sp} 4$ which in turn increase survivin expression through interaction with GC-rich cis-elements in the survivin promoter (12-14). Nuclear factor kappa B (NF-кB) is overexpressed in multiple tumor types and in some leukemia cell lines, expression of survivin is regulated by NF- $\mathrm{B}$ (15). In other leukemia cell lines, Krüppel-like factor 5 (KLF5) upregulates survivin expression and inhibits p53 which mediates suppression of survivin $(16,17)$.

Several studies report that survivin overexpression is a negative prognostic factor for cancer patient survival $(3,18-22)$. For example, increased nuclear (but not cytosolic) survivin expression was associated with a decreased overall survival for breast cancer patients (18). Survivin expression in tumors is not only a negative prognostic factor, but expression of this gene has also been linked to drug resistance associated with chemotherapy and radiotherapy (23-30). Resistance to antiandrogen and cisplatin therapy for treatment of prostate cancer is mediated by survivin $(23,24)$ and taxol resistance has also been linked to induction of survivin in cancer cell lines and tumors $(25,26)$. Radiotherapy is important for treating several types of tumors and radioresistance is related, in part, to induction of survivin in tumors undergoing radiotherapy (27-30). These observations suggest that survivin may be an important chemotherapeutic target for cancer chemotherapy 
and agents that decrease survivin expression could also serve to ameliorate drug- and radiotherapy-resistant tumors in which survivin expression is increased.

Research in this laboratory has identified a series of 1,1bis(3'-indolyl)-1-( $p$-substituted phenyl) methanes (C-DIMs) that inhibit pancreatic, colon, prostate, bladder and breast cancer cell and tumor growth (31-36). C-DIMs containing $p$-phenyl, $p$-t-butyl and $p$-trifluoromethyl substituents activate peroxisome proliferator-activated receptor $\gamma(\operatorname{PPAR} \gamma)(31-34)$, whereas $p$-methoxy and unsubstituted C-DIMs activate the orphan receptor Nur77 $(35,36)$. Other receptor-inactive C-DIMs including 1,1-bis(3'-indolyl)-1-( $p$-bromophenyl)methane (DIM-C-pPhBr) and the corresponding 2,2'-dimethyl derivative (2,2'-diMeDIM-C-pPhBr) also induce apoptosis in cancer cells through activation of ER stress $(37,38)$. In this study, we demonstrate that DIM-C-pPhBr and 2,2'-diMeDIM$\mathrm{C}$-pPhBr decrease survivin expression in pancreatic and colon cancer cells and in combination with radiotherapy, these compounds decrease radioresistance and inhibit radiationinduced survivin expression.

\section{Materials and methods}

Chemicals, antibodies, plasmids, and reagents. C-DIMs were synthesized in this laboratory from the condensation of indole or substituted indole plus a substituted benzaldehyde derivative and confirmed by gas chromatography-mass spectrometry as described previously $(31,37,38)$. Cleaved poly (ADP-ribose) polymerase (PARP) antibody was obtained from Cell Signaling (Danvers, MA). Survivin antibody was purchased from R\&D Systems (Minneapolis, MN); ß-actin antibodies were purchased from Sigma-Aldrich (St. Louis, MO); and proteasome inhibitor MG132 was purchased from Calbiochem (San Diego, CA). The pSurvivin-269 constructs containing survivin promoter inserts (positions -269 to +49 ) linked to luciferase reporter gene was kindly provided by Dr M. Zhou (Emory University, Atlanta, GA). Reporter lysis buffer and luciferase reagent for luciferase studies were purchased from Promega (Madison, WI). ß-galactosidase ( $($-gal) reagent was obtained from Tropix (Bedford, MA). Lipofectamine reagent was supplied by Invitrogen (Carlsbad, CA). Western lightning chemiluminescence reagent was from Perkin-Elmer Life Sciences (Boston, MA).

Cell lines. SW480 human colon carcinoma cell lines were provided by Dr Stanley Hamilton (M.D. Anderson Cancer Center, Houston, TX). Panc28 cell line was a generous gift from Dr Paul Chiao, The University of Texas M.D. Anderson Cancer Center (Houston, TX). Human pancreatic Panc1 cancer cell line were obtained from the American Type Culture Collection (Manassas, VA). The L3.6pl cell line was developed at The University of Texas M.D. Anderson Cancer Center. Cell lines were maintained in DMEM/F-12 (Sigma, St. Louis, MO) supplemented with $2.2 \%$ sodium bicarbonate, $2.2 \%$ bovine serum albumin, $5 \%$ fetal bovine serum, and $10 \mathrm{ml} / 1$ of $100 \mathrm{X}$ antibiotic antimycotic solution (Sigma). Cells were maintained at $37^{\circ} \mathrm{C}$ in the presence of $5 \% \mathrm{CO}_{2}$.

Cell proliferation assay. Pancreatic and colon cancer cells $\left(3 \times 10^{4}\right.$ per well) were plated in 12 -well plates and allowed to attach for $24 \mathrm{~h}$. The medium was then changed to DMEM/ Ham's F-12 medium containing 2.5\% charcoal-stripped FBS, and either vehicle (DMSO) or different concentrations of the compound were added. Cells were then trypsinized and counted after $24 \mathrm{~h}$ using a Coulter Z1 cell counter. Each experiment was done in triplicate, and results were expressed as means $\pm \mathrm{SE}$ for each set of experiments.

Transfection and luciferase assay. Colon cancer cells were plated in 12-well plates at $1 \times 10^{5}$ per well in DMEM/Ham's F-12 media supplemented with $2.5 \%$ charcoal-stripped FBS. After 16-20 h, reporter gene constructs [i.e. pSurvivin-269 (0.04 Ag) and B-gal (0.04 Ag)] were transfected by Lipofectamine (Invitrogen) according to the manufacturer's protocol. Five hours after transfection, the transfection mix was replaced with complete media containing either vehicle (DMSO) or the indicated compound for 20-22 h. Cells were then lysed with $100 \mu \mathrm{l}$ of $1 \mathrm{X}$ reporter lysis buffer, and $30 \mu \mathrm{l}$ of cell extract were used for luciferase and B-gal assays. Lumicount was used to quantitate luciferase and $\beta$-gal activities, and the luciferase activities were normalized to ß-gal activity.

Western blot analyses. Colon and pancreatic cancer cells were seeded in DMEM:Ham's F-12 medium. Twenty-four hours later, cells were treated with either vehicle (DMSO) or the indicated compounds for $24 \mathrm{~h}$ or pretreated with the proteasome inhibitor, MG132 $(10 \mu \mathrm{M})$ for $1 \mathrm{~h}$ and then treated with the compounds. Cells were lysed using high-salt buffer and Protease Inhibitor Cocktail. Protein lysates were separated on $12 \%$ SDS-PAGE $120 \mathrm{~V}$ for $4 \mathrm{~h}$. Proteins were transferred onto polyvinylidene difluoride (PVDF) membranes by wet electroblotting and the membranes were incubated with primary antibody. After washing with TBST, the PVDF membrane was incubated with secondary antibody in 5\% TBST-Blotto and the membrane was washed with TBST for $10 \mathrm{~min}$, incubated with chemiluminescence substrate for $1 \mathrm{~min}$, and exposed to Kodak autoradiography film.

Irradiation. Colon and pancreatic cancer cells were plated and exposed to varying doses of $\gamma$-radiation generated from a Theratron 80 cobalt-60 teletherapy machine (Atomic Energy of Canada) with a dose rate of $80.166 \mathrm{cGy} / \mathrm{min}$ (same as 0.8016 Gray per minute or $80.166 \mathrm{rads} / \mathrm{min}$ ), for a $30 \times 30 \mathrm{~cm}$ field, at a source-surface distance of $80 \mathrm{~cm}$. The irradiated cells were then treated with the indicated compounds after $8 \mathrm{~h}$, and cells were counted or lysates were obtained after the indicated treatment times.

Real-time PCR. Total RNA was isolated using the RNeasy Protect Mini kit (Qiagen, Valencia, CA) according to the manufacturer's protocol. RNA was eluted with $30 \mu \mathrm{l}$ of RNase-free water and stored at $-80^{\circ} \mathrm{C}$. RNA was reversetranscribed using Superscript II reverse transcriptase (Invitrogen) according to the manufacturer's protocol. cDNA was prepared from the SW480 colon and Panc28 pancreatic cancer cell lines at different time intervals using a combination of oligodeoxythymidylic acid and dNTP mix (Applied Biosystems, Foster City, CA) and Superscript II (Invitrogen). Survivin primers (forward 5'-ATG GCC GAG GCT GGC 
A
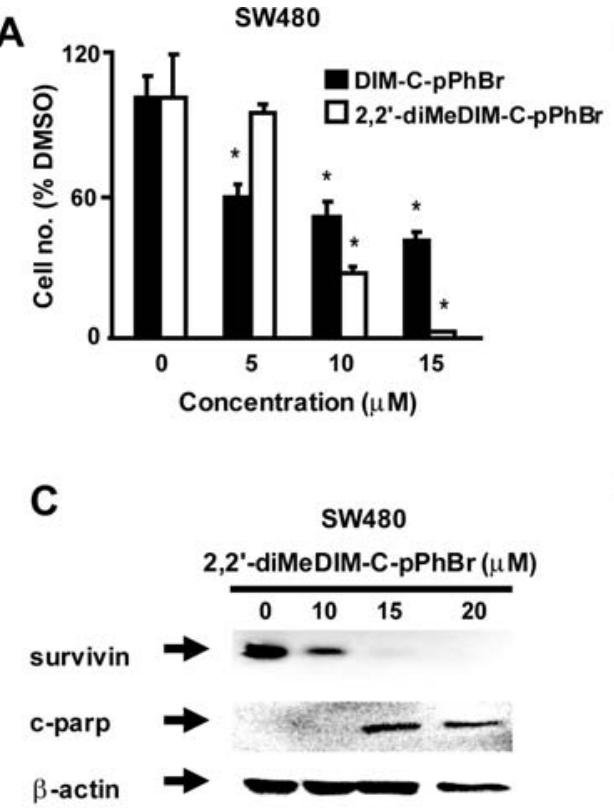

B

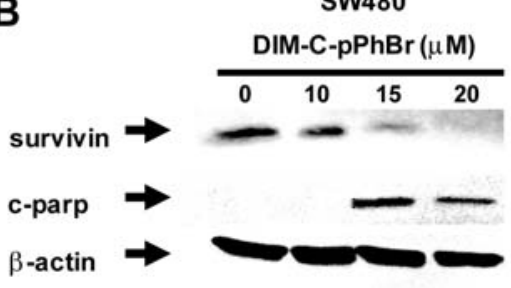

D

Figure 1. Effects of C-DIMs on SW480 cell proliferation and expression of survivin and cleaved PARP (c-parp). Concentration-dependent effects on cell proliferation (A) and survivin and c-parp protein expression (B and C). Cells were treated with DMSO and different concentrations of DIM-C-pPhBr or 2,2'-diMeDIM-C-pPhBr for $24 \mathrm{~h}$. Cells were counted (A) or whole cell lysates were analyzed by Western blot analyses as described in Materials and methods. (D) Survivin mRNA levels. Cells were treated with DMSO or 10-20 $\mu \mathrm{M}$ of C-DIM compounds, and survivin mRNA levels were determined by real-time PCR as described in Materials and methods. *A significantly $(\mathrm{p}<0.05)$ decreased response is indicated. B-actin served as a loading control for all Western blot analyses in Figs. 1-6.

TTC ATC-3'; reverse 5'-ACG GCG CAC TTT CTT CGC AGT T-3') were acquired from IDT (Skokie, IL). Each PCR was carried out in triplicate in a $20-\mu 1$ volume using SYBR Green Master mix (Applied Biosystems) for $15 \mathrm{~min}$ at $95^{\circ} \mathrm{C}$ for initial denaturing, followed by 40 cycles of $95^{\circ} \mathrm{C}$ for $30 \mathrm{sec}$ and $60^{\circ} \mathrm{C}$ for $1 \mathrm{~min}$ in the ABI PRISM 7500 sequence detection system (Applied Biosystems). Values for each gene were normalized to expression levels of TATA-binding protein (TBP).

\section{Results}

Treatment of colon and pancreatic cancer cells with DIM-C$\mathrm{pPhBr}$ or 2,2'-diMeDIM-C-pPhBr induces apoptosis and ER stress $(37,38)$ and results in Fig. 1A show that after treatment of SW480 cells with these compounds for $24 \mathrm{~h}$, there was significant concentration-dependent decrease in cell proliferation. Both $\mathrm{C}$-DIMs decreased cell numbers at concentrations of 10 or $15 \mu \mathrm{M}$ and at a concentration of $5 \mu \mathrm{M}$, DIM-C-pPhBr also inhibited SW480 cell growth, whereas 2,2'-diMeDIM-C-pPhBr was inactive. Fig. 1B and C show that both compounds also induce caspase-dependent PARP cleavage (15 and $20 \mu \mathrm{M})$ and at these same concentrations there was a parallel decrease in survivin expression in SW480 cells. In addition, we also observed that both C-DIM compounds decreased survivin mRNA expression after treatment for $24 \mathrm{~h}$ (Fig. 1D).

DIM-C-pPhBr and 2,2'-diMeDIM-C-pPhBr also inhibited Panc28 pancreatic cancer cell growth (Fig. 2A) and significant inhibition was observed at concentrations of 15-20 $\mu \mathrm{M}$.
DIM-C-pPhBr and 2,2'-diMeDIM-C-pPhBr also induced PARP cleavage and decreased survivin protein levels in Panc28 cells (Fig. 2B and C) and this was also accompanied by decreased survivin mRNA levels. All of these responses were observed after treatment of SW480 or Panc28 cells for $24 \mathrm{~h} . \mathrm{IC}_{50}$ values for growth inhibition after treatment with DIM-C-pPhBr and 2,2'-diMeDIM-C-pPhBr were 10.8 and $8.3 \mu \mathrm{M}$ (SW480) and 9.4 and $8.8 \mu \mathrm{M}$ (Panc28), respectively.

We also investigated the time-dependent effects of DIM-C-pPhBr and 2,2'-diMeDIM-C-pPhBr on survivin protein and cleaved PARP expression using a relatively high concentration $(20 \mu \mathrm{M})$ of both compounds in order to determine differences between the temporal expression of both proteins. In SW480 cells, $20 \mu \mathrm{M}$ DIM-C-pPhBr and 2,2'-diMeDIM-C-pPhBr decreased levels of survivin protein within $2 \mathrm{~h}$ after treatment, whereas cleaved PARP protein was observed only after treatment for $12 \mathrm{~h}$ (Fig. 3A and B). Similar results were observed in Panc28 cells (Fig. 3C and D); however, the extent of survivin degradation after treatment for $2 \mathrm{~h}$ was lower in Panc28 compared to SW480 cells. These results show that there was a lag between the loss of survivin and induction of cleaved PARP in both cell lines.

Fig. 4A and B illustrate the effects of $20 \mu \mathrm{M}$ DIM-C-pPhBr and 2,2'-diMeDIM-C-pPhBr on survivin mRNA levels in SW480 and Panc28 cells. Both compounds either had no effect or induced survivin mRNA levels after treatment of SW480 or Panc28 cells for $2 \mathrm{~h}$; significant inhibition of survivin mRNA levels was observed in SW480 and Panc28 cells after $12 \mathrm{~h}$; however, the magnitude of survivin mRNA repression was more pronounced in the colon cancer cells. 
A

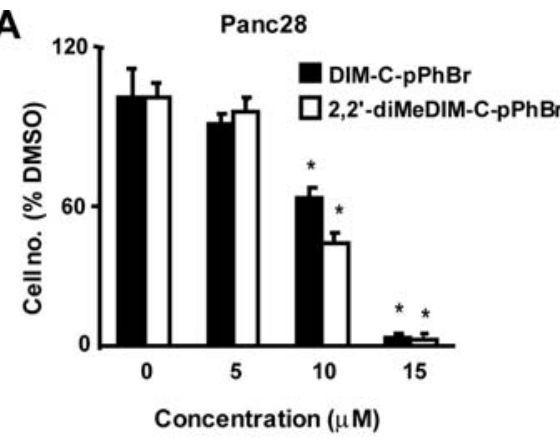

B

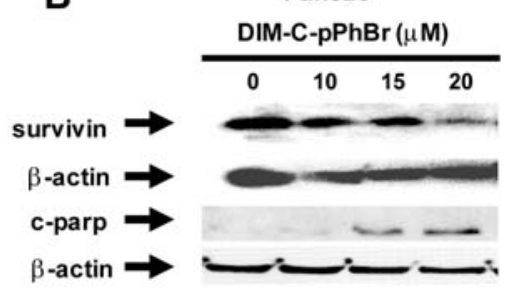

D

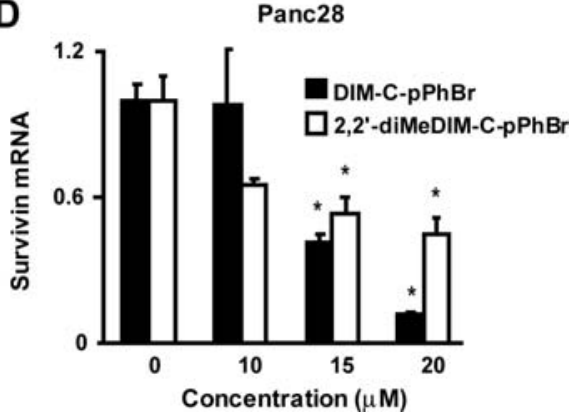

Figure 2. Effects of C-DIMs on Panc28 cell proliferation and expression of survivin and c-parp. Concentration-dependent effects on cell proliferation (A) and survivin and c-parp protein expression (B and C). Cells were treated with DMSO and different concentrations of DIM-C-pPhBr or 2,2'-diMeDIM-C-pPhBr for $24 \mathrm{~h}$. Cells were counted (A) or whole cell lysates were analyzed by Western blot analyses aals as described in Materials and methods. (D) Survivin mRNA levels. Cells were treated with DMSO or 10-20 $\mu \mathrm{M}$ of C-DIM compounds, and survivin mRNA levels were determined by real-time PCR as described in Materials and methods. *A significantly $(\mathrm{p}<0.05)$ decreased response is indicated.

A

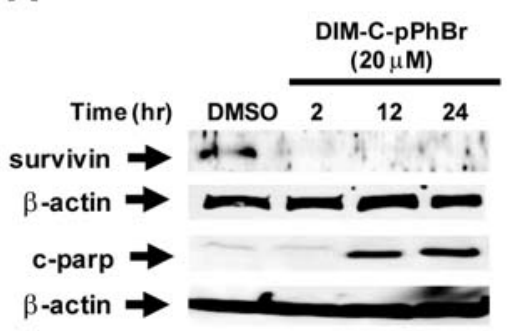

C

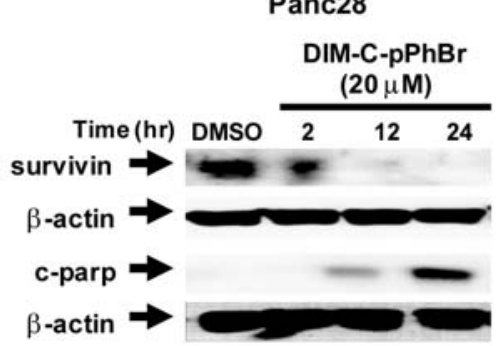

B SW480

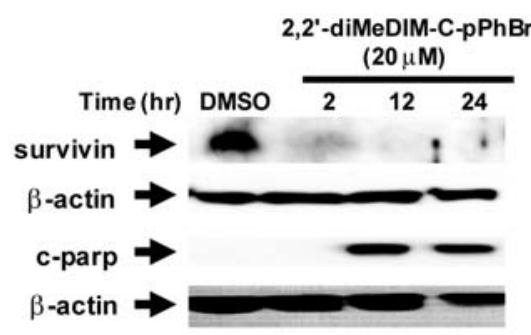

D

Panc28

2,2'-diMeDIM-C-pPhBr

$(20 \mu \mathrm{M})$

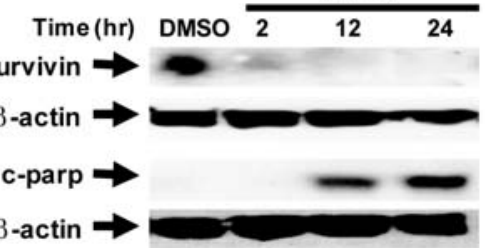

Figure 3. Time course effects of DIM-C-pPhBr $(20 \mu \mathrm{M})$ and 2,2'-diMeDIM-C-pPhBr $(20 \mu \mathrm{M})$ on survivin and c-parp expression. SW480 cells were treated with DIM-C-pPhBr (A) or 2,2'-diMeDIM-C-pPhBr (B) and Panc28 cells were treated with DIM-C-pPhBr (C) or 2,2-diMeDIM-C-pPhBr (D) for 2, 12 or 24 h. DMSO treatment served as a vehicle control. Whole cell lysates were analyzed by Western blot analyses as described in Materials and methods.

Thus, the effects of DIM-C-pPhBr and 2,2'-diMeDIM-C-pPhBr on survivin mRNA levels were observed at later time-points compared to the rapid downregulation (within $2 \mathrm{~h}$ ) of survivin protein (Fig. 3). We also confirmed that DIM-C-pPhBr and 2,2'-diMeDIM-C-pPhBr decreased luciferase activity in SW480 cells transfected with pSurvivin-269, a construct containing the -269 to +49 region of the survivin promoter (Fig. 4C). Results were not obtained in Panc28 cells due to low transfection efficiencies in this cell line. Since DIM-C-pPhBr and 2,2'-diMeDim-C-pPhBr decreased survivin protein but not 
A

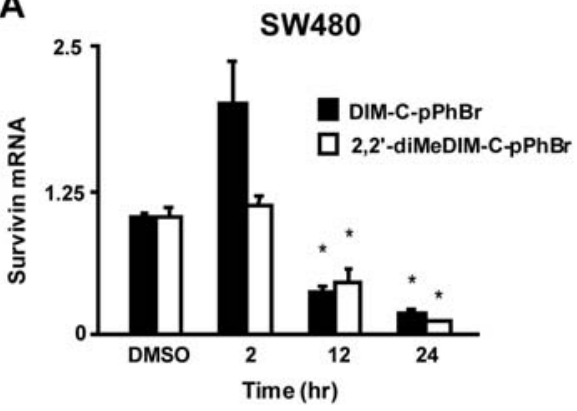

C SW480 pSurvivin (269)

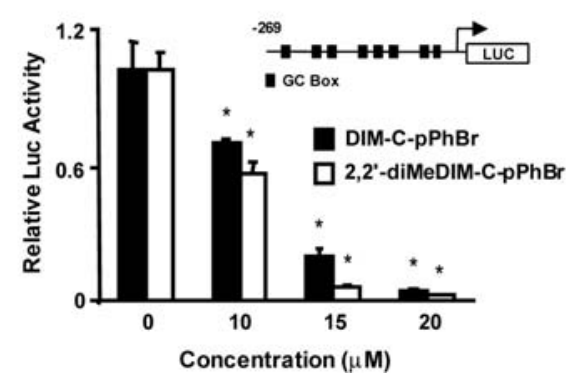

B

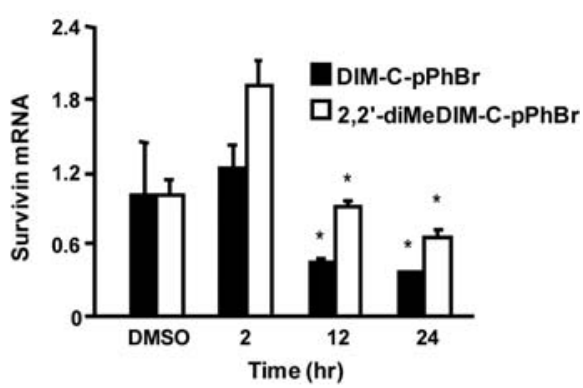

D

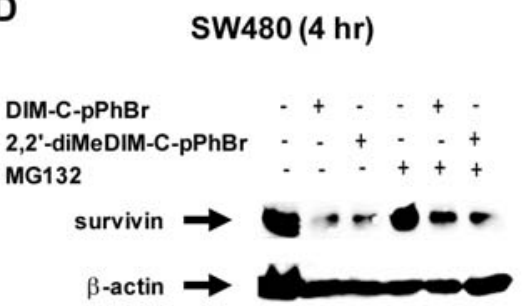

Figure 4. C-DIM-dependent effects on survivin expression. Changes in survivin mRNA expression in SW480 (A) and Panc28 (B) cells. Cells were treated with $20 \mu \mathrm{M}$ DIM-C-pPhBr or 2,2'-diMeDIM-C-pPhBr for $24 \mathrm{~h}$, and survivin mRNA levels were determined by real-time PCR as described in Materials and methods. (C) Effects on the survivin promoter. SW480 cells were transfected with pSurvivin(269) and treated with DMSO or the C-DIM compounds. Luciferase activity was determined as described in Materials and methods. (D) Effects of MG132. SW480 cells were treated with DMSO, C-DIM compounds alone $(20 \mu \mathrm{M}), 10 \mu \mathrm{M}$ MG132, or a combination of C-DIMs plus MG132 for $4 \mathrm{~h}$. Whole cell lysates were analyzed by Western blot analyses as described in Materials and methods. *Significantly $(\mathrm{p}<0.05)$ decrease mRNA levels or luciferase activity (compared to DMSO) is indicated.

A

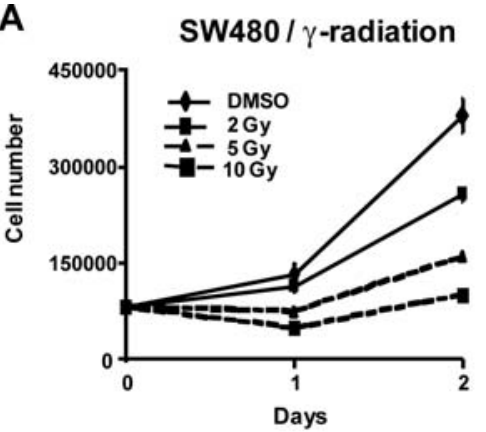

C

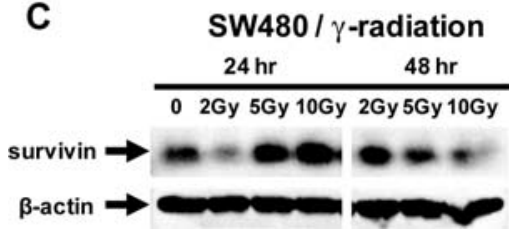

B

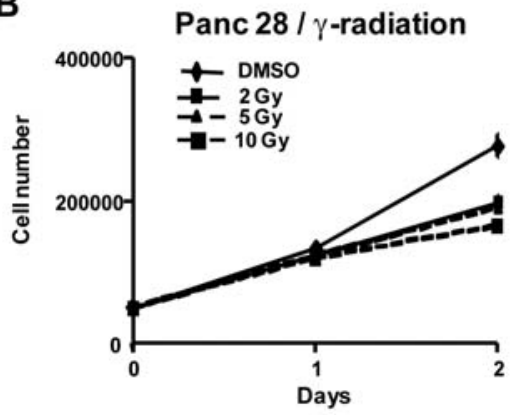

D

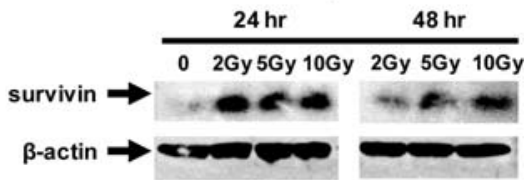

Figure 5. Effects of $\gamma$-radiation of cell proliferation and survivin expression. SW480 (A) and Panc28 (B) cell growth and expression of survivin in SW480 (C) and Panc28 (D) cells. Cells were treated with DMSO (control) and irradiated with 2, 5 or 10 Gy for 24 or 48 h, and cell number and survivin protein expression (from whole cell lysates) were determined as described in Materials and methods.

mRNA levels within $2 \mathrm{~h}$ after treatment, we investigated the effects of these compounds alone and in combination with the proteasome inhibitor MG132 after treatment of SW480 cells for $4 \mathrm{~h}$ (Fig. 4D). The results show that C-DIMdependent downregulation of survivin protein was partially reversed by the proteasome inhibitor, suggesting that activation of proteasomes contributed to the early decrease in survivin expression.
Since DIM-C-pPhBr and 2,2'-diMeDIM-C-pPhBr inhibit survivin protein expression, the interactions of these compounds with radiotherapy were investigated. Fig. 5A illustrates the effects of $\gamma$-radiation on proliferation of SW480 cells. Cells were administered at doses of 2, 5 and 10 Gy using a Theatron 80 cobalt- 60 teletherapy instrument and the effects of radiation on cell growth were determined after 24 and $48 \mathrm{~h}$. This cell line was responsive to radiation-induced 
A

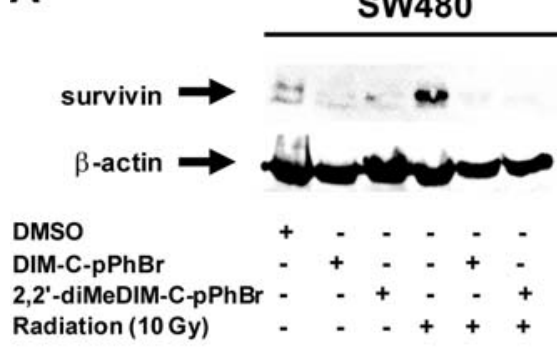

B

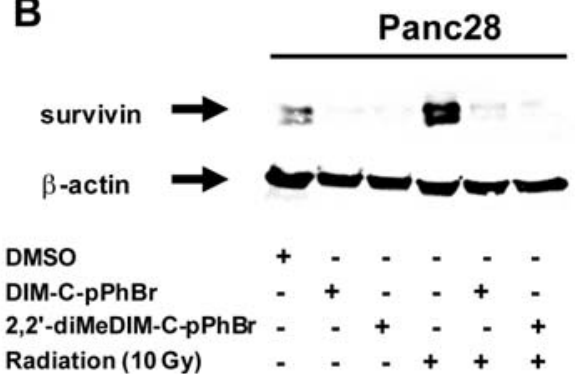

C

SW480 and Panc28

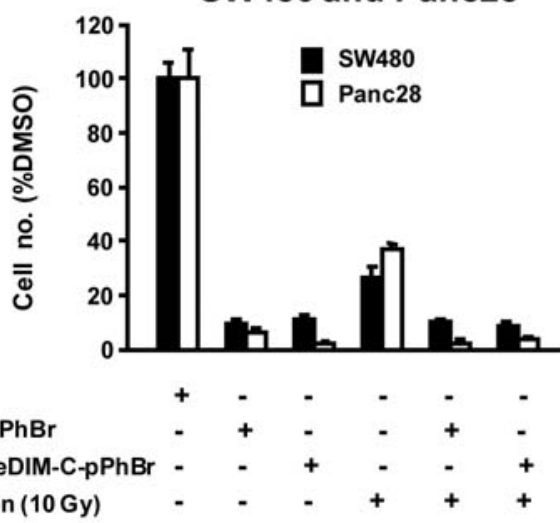

D

SW480

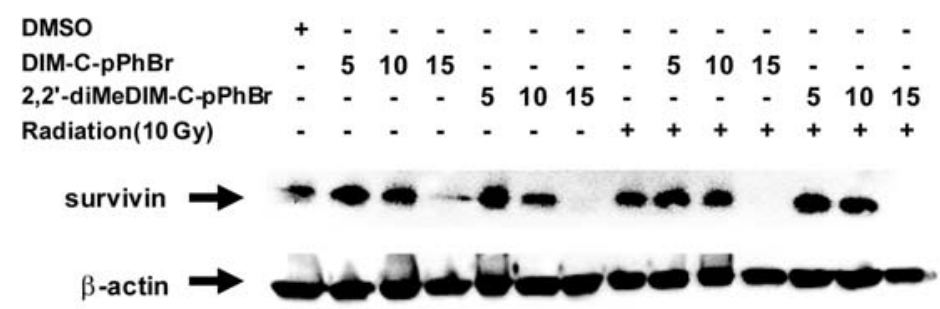

Figure 6. Interactions of $\gamma$-radiation and C-DIMs. (A) Effects of C-DIM on $\gamma$-radiation-induced survivin protein expression. Cells were treated with DMSO, C-DIMs $(20 \mu \mathrm{M})$, radiation (10 Gy), or C-DIMs plus radiation for $24 \mathrm{~h}$. Whole cell lysates were analyzed by Western blot analyses as described in Materials and methods. Effects of C-DIMs and radiation on proliferation of SW480 (B) and Panc28 cells (C). Cells were treated with DMSO, C-DIMs and radiation as described in (A), and cell numbers were determined as described in Materials and methods. (D) Concentration-dependent effects of C-DIMs on $\gamma$-radiationinduced survivin protein expression. SW480 cells were treated with DMSO; 5, 10 or $15 \mu \mathrm{M}$ DIM-C-pPhBr or 2,2'-diMeDIM-C-pPhBr alone; or in combination with $\gamma$-radiation for $24 \mathrm{~h}$. Whole cell lysates were analyzed by Western blot analyses as described in Materials and methods.

inhibition of cell growth and after $24 \mathrm{~h}$, significant inhibition was observed using 5 and 10 Gy (but not 2 Gy) and all three doses of radiation inhibited cell growth after $48 \mathrm{~h}$. Using a similar protocol, $\gamma$-radiation also inhibited Panc28 cell proliferation (Fig. 5B); however, this cell line was clearly more resistant to radiotherapy than SW480 cells over this time period and significant growth inhibition was observed only after $24 \mathrm{~h}$. The effects of $\gamma$-radiation on survivin expression were also investigated in SW480 (Fig. 5C) and Panc28 (Fig. 5D) cells and in both cell lines, 5 and 10 Gy induced survivin expression after radiation for $24 \mathrm{~h}$, whereas induction of survivin was either decreased or not observed after $48 \mathrm{~h}$. $\gamma$-radiation also induced survivin and decreased proliferation of Panc1 and L3.6pl pancreatic cells and both cell lines were more responsive than Panc28 cells to the antiproliferative activity of $\gamma$-radiation (Fig. 7).
The combined effects of $\gamma$-radiation and C-DIM compounds on survivin expression are summarized in Fig. 6A and B. Treatment of SW480 cells with $20 \mu \mathrm{M}$ DIM-C-pPhBr or 2,2'-diMeDIM-C-pPhBr for $24 \mathrm{~h}$ showed that the C-DIMs alone decreased survivin, $\gamma$-radiation alone increased survivin and C-DIMs in combination with radiation decreased radiation-induced survivin expression. Similar effects were observed on cell numbers in SW480 or Panc28 cells (Fig. 6C); however, the high concentrations $(20 \mu \mathrm{M})$ of the C-DIM alone significantly decreased cell proliferation so that the interactions with $\gamma$-radiation were not apparent. We also examined the effects of lower concentrations of DIM-C$\mathrm{pPhBr}$ and 2,2'-diMeDIM-C-pPhBr (5, 10 and $15 \mu \mathrm{M})$ on inhibition of $\gamma$-radiation-induced induction of survivin in SW480 cells (Fig. 6D). Inhibition was only observed using $15 \mu \mathrm{M}$ concentrations of C-DIMs and these concentrations 
A

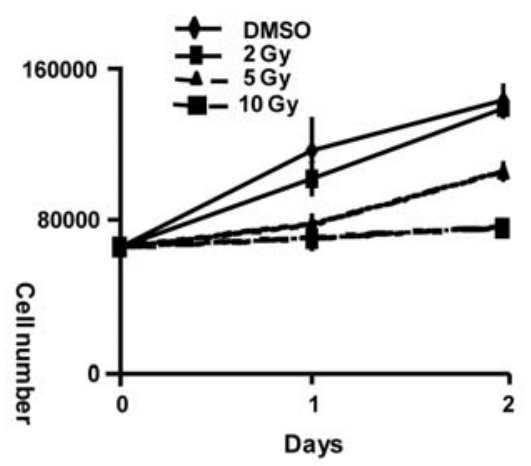

C

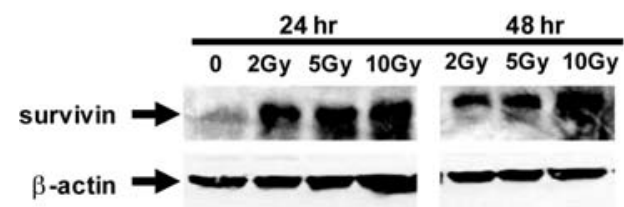

B

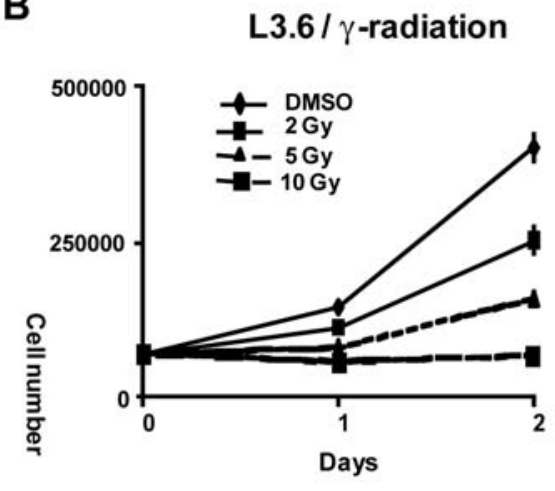

D

L3.6 / $\gamma$-radiation

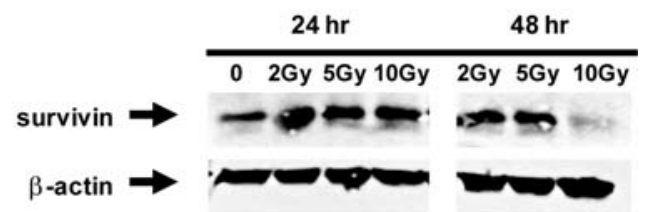

Figure 7. Effects of $\gamma$-radiation on growth of Panc1 (A) and L3.6pl (B) pancreatic cancer cells and expression of survivin in Panc1 (C) and L3.6pl (D) cells. Experiments were performed as described in Materials and methods. B-actin was used as a protein loading control.

alone also decreased levels of survivin protein. These results demonstrate that combinations of C-DIMs plus $\gamma$-radiation decrease radiation-induced survivin which plays a role in radioresistance.

\section{Discussion}

Overexpression of survivin in cancer cell lines and tumors coupled with the negative prognostic significance of this gene for the survival of patients with certain tumors has heightened interest in survivin as a potential drug target $(3,5,11)$. It is also important to evaluate the effects of both old and new drugs on survivin expression since it has been demonstrated that increased expression of survivin by taxollike drugs and radiotherapy can lead to therapy resistance (25-30). Several reports show that diverse drugs can downregulate survivin expression and these include: vitamin D3 and related analogs in leukemia and breast cancer cells (39); PPAR $\gamma$ agonists in breast cancer cells (40); doxorubicin, histone deacetylase inhibitors and lovastatin (an inhibitor of 3-hydroxy-3-methylglutaryl coenzyme A reductase) in colon cancer cells (41-43); cyclooxygenase-2 inhibitors in glioblastoma and pancreatic cancer cells (44) and $\gamma$-tocotrienol in human embryonic kidney A93 cells (45). The mechanisms of survivin downregulation by these drugs are dependent on cell context.

Previous studies in this laboratory showed that PPAR $\gamma$ active C-DIMs downregulate survivin expression in MDAMB-231 breast cancer cells after prolonged treatment; however, this was not accompanied by apoptosis (33). In contrast, DIM induced growth inhibition, apoptosis and downregulated survivin expression in MDA-MB-231 cells (46).

DIM-C-pPhBr and 2,2'-diMeDIM-C-pPhBr do not activate PPAR $\gamma$ or Nur77 but induced apoptosis in colon and pancreatic cancer cells, and activation of apoptosis by these compounds was due, in part, to ER stress-dependent upregulation of death receptor $5(37,38)$. In this study, we used these same compounds to investigate their effect on survivin expression in colon and pancreatic cancer cells and their potential interactions with $\gamma$-radiation. Like many other anticancer agents, C-DIMs potentially activate multiple pathways and we focused on some of the early responses induced by these compounds within $24 \mathrm{~h}$ after treatment. Concentrationdependent studies indicate that 10-20 $\mu \mathrm{M}$ DIM-C-pPhBr and 2,2'-diMeDIM-C-pPhBr decrease survivin protein expression in SW480 and Panc28 cells (Figs. 1 and 2) and this is accompanied by caspase-dependent PARP cleavage. Using a relatively high concentration $(20 \mu \mathrm{M})$ of the C-DIM compounds demonstrates that survivin downregulation occurs within $2 \mathrm{~h}$ after treatment in both SW480 and Panc28 cells (Fig. 3), whereas in the same experiment PARP cleavage is not observed until a later time-point. This does not necessarily completely uncouple loss of survivin with induction of caspase-dependent PARP cleavage but indicates at least that this rapid downregulation of survivin is not paralleled by PARP cleavage. Interestingly, we also observed that rapid downregulation of survivin protein in SW480 and Panc28 cells treated with DIM-C-pPhBr or 2,2'-diMeDIM-C-pPhBr was not accompanied by decreased survivin mRNA levels after $2 \mathrm{~h}$ since decreased transcription was not observed until 12-24 h after treatment in both cell lines (Fig. 4). Moreover, the proteasome inhibitor MG132 blocked C-DIM-induced downregulation of survivin protein after treatment of SW480 cells for $4 \mathrm{~h}$ (Fig. 4D). These results suggest that the C-DIM compounds downregulate survivin expression by both transcription-independent and -dependent pathways, and current studies are focused on the mechanisms associated with activation of these pathways by C-DIMs.

Resistance to radiotherapy is a serious concern in cancer therapy and there is evidence that induction of survivin after 
radiation is a resistance factor $(29,30)$. In this study, we used a Theatron 80 cobalt-60 teletherapy instrument which emits $\gamma$-radiation to investigate whether this type of radiation does indeed increase survivin expression in SW480 and Panc28 cells. $\gamma$-radiation with 2-10 Gy decreased proliferation of both Panc28 and SW480 cells; however, it was evident that the latter cells were more responsive to the growth inhibitory effects of $\gamma$-radiation (Fig. 5A and B). $\gamma$-radiation decreased survivin protein expression in both cell lines after $24 \mathrm{~h}$ and this was also observed in Panc28 cells after 48 h (Fig. 5C and D). Similar but not identical responses were also observed in two additional pancreatic cancer cell lines (Panc1 and L3.6pl) and survivin protein was increased in these cells after $24 \mathrm{~h}$ at doses of 2, 5 and 10 Gy (Fig. 7). These results clearly demonstrate that $\gamma$-radiation induces survivin expression in Panc28 pancreatic and SW480 colon cancer cells as previously reported in other cell lines $(29,30)$. Moreover, in irradiated SW480 and Panc28 cells, the increased expression of survivin was decreased in cells co-treated with $20 \mu \mathrm{M}$ DIM-C-pPhBr and 2,2'-diMeDIM-C-pPhBr (Fig. 6A and B) and similar results were observed for $15 \mu \mathrm{M}$ concentrations of these same compounds (Fig. 6D). Thus, like other drugs such as vitamin D3, PPAR $\gamma$ agonists, doxorubicin, lovastatin, histone deacetylase and cyclooxygenase inhibitors (39-45), the C-DIM compounds also downregulate survivin and block $\gamma$-radiationinduced expression of survivin. Previous studies with DIM-CpPhBr and 2,2'-diMeDIM-C-pPhBr demonstrate their anticancer activity alone in both in vitro and in vivo (xenograft) pancreatic and colon cancer cells/tumors and this is due, in part, to their ER stress-dependent proapoptotic activity $(38,39)$. Results of this study demonstrate their potential clinical utility in combination with radiotherapy where the C-DIMs inhibit $\gamma$-radiation-induced survivin expression, a known marker of radiotherapy-resistance.

\section{Acknowledgements}

This research was supported by the National Institutes of Health (CA108718 and CA112337).

\section{References}

1. Altieri DC: The case for survivin as a regulator of microtubule dynamics and cell-death decisions. Curr Opin Cell Biol 18: 609-615, 2006

2. Deveraux QL and Reed JC: IAP family proteins - suppressors of apoptosis. Genes Dev 13: 239-252, 1999.

3. Stauber RH, Mann W and Knauer SK: Nuclear and cytoplasmic survivin: molecular mechanism, prognostic, and therapeutic potential. Cancer Res 67: 5999-6002, 2007.

4. Lens SM, Vader G and Medema RH: The case for Survivin as mitotic regulator. Curr Opin Cell Biol 18: 616-622, 2006.

5. Pennati M, Folini M and Zaffaroni N: Targeting survivin in cancer therapy: fulfilled promises and open questions. Carcinogenesis 28: 1133-1139, 2007.

6. Xing Z, Conway EM, Kang C and Winoto A: Essential role of survivin, an inhibitor of apoptosis protein, in T cell development, maturation, and homeostasis. J Exp Med 199: 69-80, 2004.

7. Gurbuxani S, Xu Y, Keerthivasan G, Wickrema A and Crispino JD: Differential requirements for survivin in hematopoietic cell development. Proc Natl Acad Sci USA 102: 11480-11485, 2005.

8. Deguchi M, Shiraki K, Inoue H, et al: Expression of survivin during liver regeneration. Biochem Biophys Res Commun 297 $59-64,2002$.
9. Chiou SK, Moon WS, Jones MK and Tarnawski AS: Survivin expression in the stomach: implications for mucosal integrity and protection. Biochem Biophys Res Commun 305: 374-379, 2003.

10. Yang L, Cao Z, Yan H and Wood WC: Coexistence of high levels of apoptotic signaling and inhibitor of apoptosis proteins in human tumor cells: implication for cancer specific therapy. Cancer Res 63: 6815-6824, 2003.

11. Zaffaroni N, Pennati M and Daidone MG: Survivin as a target for new anticancer interventions. J Cell Mol Med 9: 360-372, 2005.

12. Wu J, Ling X, Pan D, et al: Molecular mechanism of inhibition of survivin transcription by the GC-rich sequence-selective DNA binding antitumor agent, hedamycin: evidence of survivin down-regulation associated with drug sensitivity. J Biol Chem 280: 9745-9751, 2005 .

13. Li F and Altieri DC: Transcriptional analysis of human survivin gene expression. Biochem J 344: 305-311, 1999.

14. Chadalapaka G, Jutooru I, Chintharlapalli S, et al: Curcumin decreases specificity protein expression in bladder cancer cells. Cancer Res 68: 5345-5354, 2008.

15. Kawakami H, Tomita M, Matsuda T, et al: Transcriptional activation of survivin through the NF- $\mathrm{kB}$ pathway by human T-cell leukemia virus type I tax. Int J Cancer 115: 967-974, 2005.

16. Zhu N, Gu L, Findley HW, et al: KLF5 interacts with p53 in regulating survivin expression in acute lymphoblastic leukemia. J Biol Chem 281: 14711-14718, 2006.

17. Raj D, Liu T, Samadashwily G, Li F and Grossman D: Survivin repression by $\mathrm{p} 53, \mathrm{Rb}$ and $\mathrm{E} 2 \mathrm{~F} 2$ in normal human melanocytes. Carcinogenesis 29: 194-201, 2008.

18. Hinnis AR, Luckett JC and Walker RA: Survivin is an independent predictor of short-term survival in poor prognostic breast cancer patients. Br J Cancer 96: 639-645, 2007.

19. Karam JA, Lotan Y, Ashfaq R, Sagalowsky AI and Shariat SF: Survivin expression in patients with non-muscle-invasive urothelial cell carcinoma of the bladder. Urology 70: 482-486, 2007.

20. Shariat SF, Ashfaq R, Karakiewicz PI, Saeedi O, Sagalowsky AI and Lotan Y: Survivin expression is associated with bladder cancer presence, stage, progression, and mortality. Cancer 109: 1106-1113, 2007.

21. Adida C, Recher C, Raffoux E, et al: Expression and prognostic significance of survivin in de novo acute myeloid leukaemia. $\mathrm{Br}$ J Haematol 111: 196-203, 2000.

22. Adida C, Haioun C, Gaulard P, et al: Prognostic significance of survivin expression in diffuse large B-cell lymphomas. Blood 96: 1921-1925, 2000.

23. Nomura T, Yamasaki M, Nomura Y and Mimata H: Expression of the inhibitors of apoptosis proteins in cisplatin-resistant prostate cancer cells. Oncol Rep 14: 993-997, 2005.

24. Zhang M, Latham DE, Delaney MA and Chakravarti A: Survivin mediates resistance to antiandrogen therapy in prostate cancer. Oncogene 24: 2474-2482, 2005.

25. Zaffaroni N, Pennati M, Colella G, et al: Expression of the anti-apoptotic gene survivin correlates with taxol resistance in human ovarian cancer. Cell Mol Life Sci 59: 1406-1412, 2002.

26. Ling X, Bernacki RJ, Brattain MG and Li F: Induction of survivin expression by taxol (paclitaxel) is an early event, which is independent of taxol-mediated G2/M arrest. J Biol Chem 279: 15196-15203, 2004.

27. Rodel F, Hoffmann J, Distel L, et al: Survivin as a radioresistance factor, and prognostic and therapeutic target for radiotherapy in rectal cancer. Cancer Res 65: 4881-4887, 2005.

28. Garcia-Barros M, Paris F, Cordon-Cardo C, et al: Tumor response to radiotherapy regulated by endothelial cell apoptosis. Science 300: 1155-1159, 2003.

29. Asanuma K, Moriai R, Yajima T, et al: Survivin as a radioresistance factor in pancreatic cancer. Jpn J Cancer Res 91: 1204-1209, 2000.

30. Rodel C, Haas J, Groth A, Grabenbauer GG, Sauer R and Rodel F: Spontaneous and radiation-induced apoptosis in colorectal carcinoma cells with different intrinsic radiosensitivities: survivin as a radioresistance factor. Int $\mathbf{J}$ Radiat Oncol Biol Phys 55: 1341-1347, 2003.

31. Chintharlapalli S, Papineni S and Safe S: 1,1-Bis(3'-indolyl)-1(p-substituted phenyl)methanes inhibit colon cancer cell and tumor growth through PPAR $\gamma$-dependent and PPAR $\gamma$-independent pathways. Mol Cancer Ther 5: 1362-1370, 2006. 
32. Kassouf W, Chintharlapalli S, Abdelrahim M, Nelkin G, Safe S and Kamat AM: Inhibition of bladder tumor growth by 1,1 bis(3'-indolyl)-1-(p-substituted phenyl)methanes: a new class of peroxisome proliferator-activated receptor $\gamma$ agonists. Cancer Res 66: 412-418, 2006.

33. Vanderlaag K, Su Y, Frankel AE, et al: 1,1-Bis(3'-indolyl)-1-(psubstituted phenyl)methanes inhibit proliferation of estrogen receptor-negative breast cancer cells by activation of multiple pathways. Breast Cancer Res Treat 109: 273-283, 2008.

34. Ichite N, Chougule MB, Jackson T, Fulzele SV, Safe S and Singh M: Enhancement of docetaxel anticancer activity by a novel diindolylmethane compound in human non-small cell lung cancer. Clin Cancer Res 15: 543-552, 2009.

35. Chintharlapalli S, Burghardt R, Papineni S, Ramaiah S, Yoon K and Safe S: Activation of Nur77 by selected 1,1-Bis(3'-indolyl)1 -(p-substituted phenyl)methanes induces apoptosis through nuclear pathways. J Biol Chem 280: 24903-24914, 2005.

36. Cho SD, Yoon K, Chintharlapalli S, et al: Nur77 agonists induce proapoptotic genes and responses in colon cancer cells through nuclear receptor-dependent and independent pathways. Cancer Res 67: 674-683, 2007

37. Lei P, Abdelrahim M, Cho SD, Liu S, Chintharlapalli S and Safe S: 1,1-Bis(3'-indolyl)-1-(p-substituted phenyl)methanes inhibit colon cancer cell and tumor growth through activation of c-Jun N-terminal kinase. Carcinogenesis 29: 1139-1147, 2008.

38. Lei P, Abdelrahim M, Cho SD, Liu X and Safe S: Structuredependent activation of endoplasmic reticulum stress-mediated apoptosis in pancreatic cancer by 1,1-bis(3'-indoly)-1-(p-substituted phenyl)methanes. Mol Cancer Ther 7: 3363-3372, 2008.

39. Li F, Ling X, Huang H, et al: Differential regulation of survivin expression and apoptosis by vitamin D3 compounds in two isogenic MCF-7 breast cancer cell sublines. Oncogene 24: 1385-1395, 2005.
40. Lu M, Kwan T, Yu C, et al: Peroxisome proliferator-activated receptor $\gamma$ agonists promote TRAIL-induced apoptosis by reducing survivin levels via cyclin D3 repression and cell cycle arrest. J Biol Chem 280: 6742-6751, 2005.

41. Esteve PO, Chin HG and Pradhan S: Molecular mechanisms of transactivation and doxorubicin-mediated repression of survivin gene in cancer cells. J Biol Chem 282: 2615-2625, 2007.

42. Nawrocki ST, Carew JS, Douglas L, Cleveland JL, Humphreys R and Houghton JA: Histone deacetylase inhibitors enhance lexatumumab-induced apoptosis via a p $21^{\mathrm{Cip} 1}$-dependent decrease in survivin levels. Cancer Res 67: 6987-6994, 2007.

43. Kaneko R, Tsuji N, Asanuma K, Tanabe H, Kobayashi D and Watanabe N: Survivin down-regulation plays a crucial role in 3-hydroxy-3-methylglutaryl coenzyme A reductase inhibitorinduced apoptosis in cancer. J Biol Chem 282: 19273-19281, 2007.

44. Pyrko P, Soriano N, Kardosh A, et al: Downregulation of survivin expression and concomitant induction of apoptosis by celecoxib and its non-cyclooxygenase-2-inhibitory analog, dimethyl-celecoxib (DMC), in tumor cells in vitro and in vivo. Mol Cancer 5: 19, 2006.

45. Ahn KS, Sethi G, Krishnan K and Aggarwal BB: $\gamma$-tocotrienol inhibits nuclear factor- $\mathrm{\kappa B}$ signaling pathway through inhibition of receptor-interacting protein and TAK1 leading to suppression of antiapoptotic gene products and potentiation of apoptosis. J Biol Chem 282: 809-820, 2007.

46. Rahman KW, Li Y, Wang Z, Sarkar SH and Sarkar FH: Gene expression profiling revealed survivin as a target of 3,3'-diindolylmethane-induced cell growth inhibition and apoptosis in breast cancer cells. Cancer Res 66: 4952-4960, 2006. 